\title{
Commercial contract cheating provision through micro-outsourcing web sites
}

Thomas Lancaster(1)

Correspondence: thomas@ thomaslancaster.co.uk Department of Computing, Imperial College London, London, UK

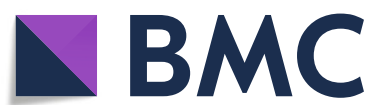

\section{Introduction}

The contract cheating industry, a term largely declared to mean the set of companies and individuals who are enabling students to have bespoke work created for assessment as if the students themselves had done completed it, is a complex beast. The industry employs heavy marketing pressure to convince students that they need these services, often presenting their offer as a support service, rather than one that is helping students to cheat by design. The industry is thought to be highly profitable for

(c) The Author(s). 2020 Open Access This article is licensed under a Creative Commons Attribution 4.0 International License, which permits use, sharing, adaptation, distribution and reproduction in any medium or format, as long as you give appropriate credit to the original author(s) and the source, provide a link to the Creative Commons licence, and indicate if changes were made. The images or other third party material in this article are included in the article's Creative Commons licence, unless indicated otherwise in a credit line to the material. If material is not included in the article's Creative Commons licence and your intended use is not permitted by statutory regulation or exceeds the permitted use, you will need to obtain permission directly from the copyright holder. To view a copy of this licence, visit http://creativecommons.org/licenses/by/4.0/. The Creative Commons Public Domain Dedication waiver (http://creativecommons.org/publicdomain/zero/1.0/) applies to the data made available in this article, unless otherwise stated in a credit line to the data. 
those running successful companies. One essay company owner has even created analogies with the market in illegal drugs by referring to themselves as an "essay dealer" (Zheng and Stokel-Walker 2018). With 15\% of students thought to purchase contract cheating solutions during their academic journey, there are no shortage of customers for the industry (Newton 2018). The potential exists for the contract cheating industry to expand still further.

Despite the extent of the contract cheating industry and its visibility to students, little has been formally published about how the industry operates, or who the writers and workers at the end of a complex chain of operations are. To address contract cheating, academia needs an increased understanding of this industry. Academia needs to appreciate what drives workers to choose to subvert academic integrity. Such research now needs to be continual and ideally supported by automated data collection and processing. As this paper will demonstrate using only a single indicative web site, the use of this site by the commercial contract cheating industry as an extra mechanism to feed student orders to it has shown dramatic changes over just a two-year period. The contract cheating industry makes changes such as these all the time in order to help ensure the its continual profitability. Such change does not happen only on one site, but on many hundreds of sites operating in the profitable but competitive contract cheating space.

This paper opens by addressing a deficiency in the contract cheating literature. It discusses terminology that can be used to describe the contract cheating industry and to detail its operations. Findings from some of the main academic papers discussing the industry and the workers supporting it are briefly explored. The focus of the paper is on two comparative studies of Fiverr.com, a micro-outsourcing web site which the contract cheating industry can advertise the provision of services to students. Many individual workers operate on this site to connect directly with customers since they can pay only a small commission to the enabling web site, rather than a much larger commission to a traditional essay mill.

The first study of contract cheating on Fiverr.com, conducted in June 2016, has already been discussed in the literature (Lancaster 2019b). The repeat comparative study was conducted in October 2018 and is discussed in this paper for the first time. The results of the study are used to motivate further work in this field and the need for continual awareness regarding the changing commercial contract cheating industry.

\section{The contract cheating industry}

\section{Contract cheating terminology}

This paper focuses on commercial contract cheating. Here money or other equivalent services are expected to change hands during the process through which a student has work completed for them.

Despite the term contract cheating having been introduced in 2006 (Clarke and Lancaster 2006), large scale academic discussions on contract cheating have only recently begun to appear. One challenge that has emerged from the way in which academic publications have been independently developed is that the terminology surrounding contract cheating is not being used consistently. In some cases, terminology has not been defined at all. 
To properly understand and address contract cheating, academia needs to improve its understanding about how the industry operates.

This paper uses the following terminology, defined particularly to match what is known about the operation of the contract cheating process:

- Contract cheating industry (or "the industry") - the overarching set of companies and individuals who are the enablers of commercial contract cheating.

- Contract cheating providers ("or providers") - the firms and individuals with whom a student buying an assignment directly interacts.

- Commercial contract cheating - contract cheating that takes place with payment in the form of money or a suitable equivalent

- Non-commercial contract cheating - contract cheating that takes place without the exchange of money or equivalent, for example through a family member completed work on behalf of a student

- Outsourcing - the process through which a contract cheating request to have assessment completed can be referred to contract cheating providers. Note outsourcing can be a legitimate business process outside of a contract cheating scenario.

- Customer - an individual requesting, or attempting to request, solutions through a contract cheating process. The customer will often be a student themselves, but may also be one of their supporters, such as a friend or family member. The customer may, on occasions, be another contract cheating provider, perhaps looking to themselves re-outsource a request (providers like these are often referred to in the literature as a "third party subcontractor")

- Workers - the individuals, or group of individuals, who are completing assessments requested through a contract cheating process (the terms "writers" and "contractors" may also be used, but it needs to be recognised that not all contract cheating is text based).

- Assessment - the overarching process through which a student's knowledge and ability is evaluated. Where a contract cheating provider is involved, this removes confidence in the assessment system that the student has themselves successfully meet the standards required of them.

- Assignment brief - the document detailing the task that a student needs to deliver as part of the assessment process. The term "assignment specification" may also be used.

- Assignment solution - the work produced for assessment. When contract cheating is involved, this means that the work may be fully, or in part, not completed by the students (the term "essay" may also be used, but again it needs to be recognised that not all contract cheating is text based and not all assessment types are essays).

- Essay mill - one type of website through which an individual can interact to place an order for an assignment solution. An essay mill may hire its own on-site workers. They may outsource their work (often referred to the in the literature as them using a third-party subcontractor). The actual operation of an essay mill is likely to be complex, with various levels of staff handling the complete marketing, order fulfilment and customer service processes.

- Outsourcing site - a site through which a request for contract cheating can be fulfilled. The site may also allow for legitimate orders that are not connected with 
academia. On some outsourcing sites, all the requests are visible to the public. Some essay mills operate using a private internal outsourcing site available only to their registered workers.

- Micro-outsourcing site - a specific type of outsourcing site, often categorised by the production of small scale and low-cost solutions.

In addition, two operational models of outsourcing sites are common in the contract cheating industry (as defined by Lancaster 2019b). These operational models are described as:

- Request model - a customer can request a service. Providers then compete against each other to operate that service, often using a reverse auction process. Elsewhere in the literature, this type of outsourcing site has been referred to as an "auction site" or an "agency site".

- Gig model - providers advertise the services they offer, sometimes with a choice of price points. Each service is known as a "Gig". Customers then place their order for that Gig. The provider may have the option to choose which orders they accept, although since elements of the detail of orders are public, they are unlikely to continue to receive orders if they turn many of these down. This wider term "Gig Economy" is now commonly used to describe the unpredictable, casual and possibly exploitative landscape in which this type of worker operates.

Both the request model and Gig model can operate within a single outsourcing site. The site discussed in the main study in this paper, Fiverr.com, is one such site that operates in this way.

Even with access to terminology, it is not always possible to comprehensively define the contract cheating industry operation, since the industry does not itself operate with consistent standards. There are elements of deception involved.

For example, a single essay mill may itself operate several different front-end sites, all part of an enhanced marketing process designed to increase its custom. One site may make it look as if it's offering students access to writers from world-leading universities. Another site may claim to be focused towards nursing students from Australia. A third site may claim to be specialised on UK history, with local writers employed. In reality, the orders often appear to go to the same set of workers, regardless of what is advertised.

A smaller scale example may see a contract cheating service advertising on a local noticeboard or classified ads website. A student looking for more information may find an elaborate essay mill style website. In fact, these sites are readily available or purchase through low-cost templates. There are detailed guides available online showing interested parties how to make money online through the contract cheating industry. The student orders, when they come in, would simply be sent to a plug-in style essay mill with whom the local provider has an affiliate commission or agreement, or perhaps re-outsourced to a request model or Gig model site. Here the small-scale provider would pocket the difference between the fee paid by the student and that paid to the third-party subcontractor.

\section{Contract cheating industry literature}

There has been little research published specific to the operation of the contract cheating industry, the marketing methods it uses or the motivations behind the writers who 
are keeping these services running. Interest has increased substantially in recent years, for example, in 2018 the International Journal for Educational Integrity actively requested articles on contract cheating for publication. There is no intent in this paper to review all literature on contract cheating, but primarily to focus on that related to the wider industry and the assignment solutions it produces for students.

Despite the idea that contract cheating is new, discussions of the challenges posed by the industry date back to at least the 1970s (Stavisky 1973). What is newer is the growth of students having easy access to contract cheating services and the pervasive levels of marketing of these services. This means that it would be unlikely that any students would be unaware that the opportunity exists for them to take academic shortcuts. The operation of the industry has been explored (Hersey and Lancaster 2015). The industry appears well-equipped to offer assignments across all academic disciplines and at levels of study from pre-university through to postgraduate level (Lancaster and Clarke 2014). Studies have begun to examine the marketing of these services (Medway et al. 2018; Ellis et al. 2018) as well as how this can be detected through the specific way that the industry presents itself (Rogerson 2017).

It has been demonstrated that students are willing to use contract cheating services. More than $50 \%$ of students said they would outsource their work if the reward, perhaps in the form of higher marks or passing assessment they would otherwise have failed, was relatively high and the cost relatively low (Rigby et al. 2015). The contract cheating industry now appears well equipped to identify students needing what they can position as extra support. The issue of the contract cheating industry using bots to identify students who have expressed that they are under pressure has emerged as a specific challenge (Amigud and Lancaster 2019). A darker side to the contract cheating industry has seen students exposed to threats of blackmail (Yorke et al. 2020).

The make-up of the workers in the contract cheating industry is of relevance to this paper. One seminal study discussed interviews with essay writers, some of whom had branched out to create their own worker network to outsource work they were offered when they were working beyond their individual capacity or when the work offered was outside their academic specialisation (Sivasubramaniam et al. 2016). The study found that graduates from western universities who were returning to their home country and using their expertise and contacts as the basis for setting up an essay mill. Sivasubramaniam's findings have been corroborated by more recent investigations, which have found contract cheating workers advertising themselves as highly qualified, with many specialising their offer to appeal to students on courses in the Business academic discipline (Lancaster 2019c).

The literature has identified nine main groups of workers involved in providing contract cheating solutions for students (Lancaster 2019b). Some individual workers may fit into multiple groups. These groups are: (1) accidental academic ghost writers, (2) business opportunists, (3) desperate individuals, (4) would-be academics, (5) internationally qualified academic ghost writers, (6) career academic ghost writers, (7) student peers, (8) previous graduates, (9) friends and family members. The existence of these groups suggests that the motivation of contract cheating workers is not always clear-cut. Some may be in this line of work due to necessity, some due to convenience and others because they have developed an aptitude for academic writing and see supporting students in this underhand manner as a legitimate profession. 
The threat of workers from Kenya being actively involved in the contract cheating industry has been identified through several sources (Lancaster 2019b; Walker 2017, 2020). In Kenya, the job of an "academic writer" is said to thought to be prestigious, with guides and information readily available showing potential workers how to get into the industry. The interest in getting a job is so great that worker accounts with contract cheating sites are sold online to those who would not usually qualify.

The pay for contract cheating workers is variable, but perhaps the biggest threat to educational standards is posed by low-cost contract cheating, since this is most affordable by students. Sources indicate that pay can be as little as \$4 USD for a freelance worker hired to write 2000 words (Lancaster 2019a). A qualified full-time worker can be hired for $\$ 84$ USD a month. With the expectation that an experienced full-time worker can write one essay a day and works 20 days per month, that equates to $\$ 4.20$ per essay, not dissimilar to the lower end of the freelance worker pay scale.

A figure of $\$ 60$ USD for a 2000 word essay may be a more typical price point for a worker employed directly by a student, or engaged through a micro-outsourcing website. A similar figure has emerged through two studies. Lancaster (2019b) identified $\$ 31.73$ per 1000 words as the most typical price charged by workers on Fiverr.com. An alternative study of larger scale providers from India, a location that seems to be another common location for contract cheating workers to be based in, operating on Freenlacer.com, found the price point there to be $\$ 29.44$ USD per 1000 words (Lancaster 2019c). Despite these low price points, the size of the contract cheating industry is likely to be substantial. In 2014, this was estimated at a minimum of $\$ 100$ million USD (Owings and Nelson 2014). At the time, that was likely an underestimate and today, it is likely to be a substantial underestimate.

Several studies have shown that purchased assignment solutions through a contract cheating process have suggested that the end-result may not actually be very good. These have included investigations into purchased essays (Lines 2016; SutherlandSmith and Dullaghan 2019) and purchased computer code (Jenkins and Helmore 2006). The overarching consensus from those sources is that, whilst it is possible to purchase high quality assignment solutions, the grade obtained for this is much more likely to be closer to the pass standard, regardless of what is advertised by contract cheating services. Some purchased essays and assignment solutions may be given a failing grade. This supports the idea that contract cheating workers are writing assignment solutions quickly and often superficially, particularly since the pay in low and they would need to deliver academic work in bulk to make a reasonable income.

The recommendations regarding how academia should address contract cheating continue to evolve, with improved assessment design and co-working with students often featuring heavily in suggestions given in the literature (Lancaster and Clarke 2007, 2016). National quality assurance bodies have begun to involve themselves in the discussion of standards and to issue their often guidance, for example that guidance issued by the United Kingdom's Quality Assurance Agency (2017).

\section{Contract cheating on a micro-outsourcing website}

\section{Fiverr.com}

The analysis reported in this paper focused on data that is available to the public collected from the micro-outsourcing site Fiverr.com. The data represents a view of all the 
reviewed transactions going through the site, but this is only partial since not all transactions are reviewed or visible.

On Fiverr.com, providers can advertise Gigs for sale covering a wide range of services. Gigs are priced at a minimum of \$ USD, although they can be priced higher depending on the price the provider feels that they can achieve and the volume of work. Gigs can also contain upsells, for instance a customer can pay more to bring an order to the front of the queue.

The majority of Gigs on Fiverr.com are not connected with contract cheating, but it is still easy to find contract cheating Gigs on offer by searching for terms involving essays, assignments, dissertations, academic writing and research. For example, Fig. 1 shows a selection of the Gigs available under the search term "essay help".

The Gigs shown in Fig. 1, which appeared during a simple search, are indicative of the wide range of contract cheating opportunities available on Fiverr.com. They cover a variety of specific academic disciplines, including medicine, history, religion and psychology, as well as assisting people to obtain university places in the first place. The term "help" used here as part of the search makes it unclear if these providers are offering a complete contract cheating solution, but a check of the full details of those Gigs removes the illusion that these are anything other than services than are writing essays for students. The advertising of contract cheating services on Fiverr.com is more blatant than those of many essay mills that skirt around the law by claiming to only be offering "sample essays".

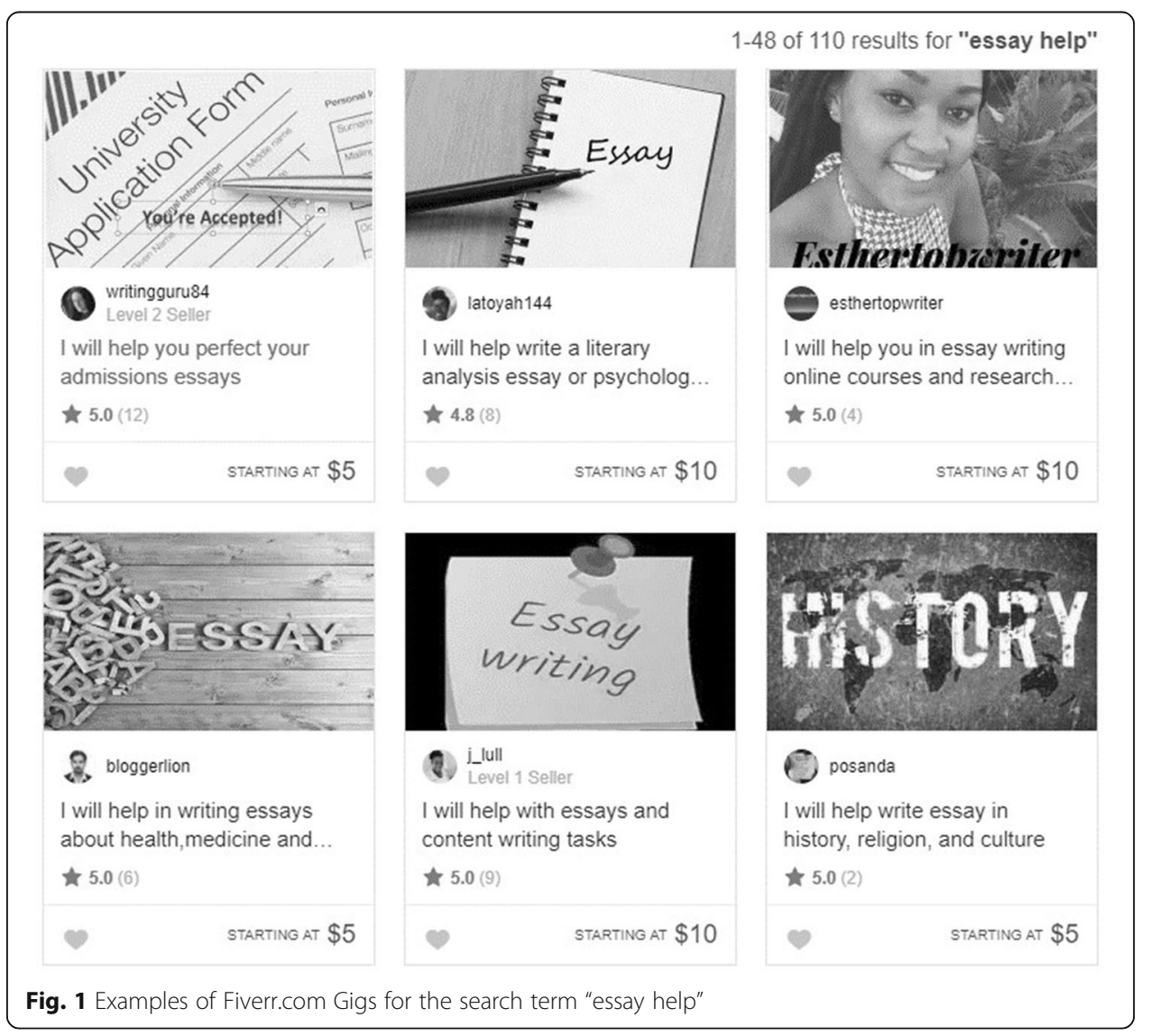


More information about the individual Gigs is available, as is a link to the worker profile. Figure 2 shows some of the visible information from a further provider who is offering a Gig specialising in writing essays for students on nursing courses.

The provider of nursing essays shown in Fig. 2 offers three levels of service in their Gig, with a starting point of $\$ 10$ USD for 250 words. They claim to be based in Kenya, a common location for contract cheating workers, with 104 reviews across all their Gigs. This specific Gig has 26 reviews, which provides a lower bound of the number of orders they have previously completed. There are four more orders currently being worked on. Other available information shows the most recent order across all of the provider's Gigs as having been delivered $14 \mathrm{~min}$ ago. The provider says that they gained an MSc from a university in the United States in 2000 and have subsequently completed certification in mechatronics. One of their other Gigs says that they will "embellish cover letters and resumes without lying". Interestingly, the Gig details including the word "we" which suggests that there may be a team involved, although this is contradicted by the provider's profile page. The reviews for the provider are positive, showing an average rating of 4.9 out of 5 for the Gig. The timing of the reviews suggests that the provider is producing around four essays per week for this single Gig alone. This figure does not take into account their other active Gigs.

As well as contract cheating services, a selection of alternative Gigs can be purchased on Fiverr.com that would give students an unfair advantage. For example, there are sellers providing access to Turnitin accounts, allowing students to who wish to plagiarise to repeatedly edit their assignment solutions until they appear original and would no longer raise suspicion.

\section{Methodology}

Data on contract cheating providers on Fiverr.com was manually collected in two periods, June 2016 and October 2018. For clarity, an initial analysis of the data collected in June 2016 has already been published (Lancaster 2019b). The data collection process for this paper uses the same methodology as the earlier paper. This allows for the change in approach as to how the contract cheating industry uses this microoutsourcing website to be reported on. As such, the methodological detail here is deliberately presented in a brief format. A full description of the methodology, the

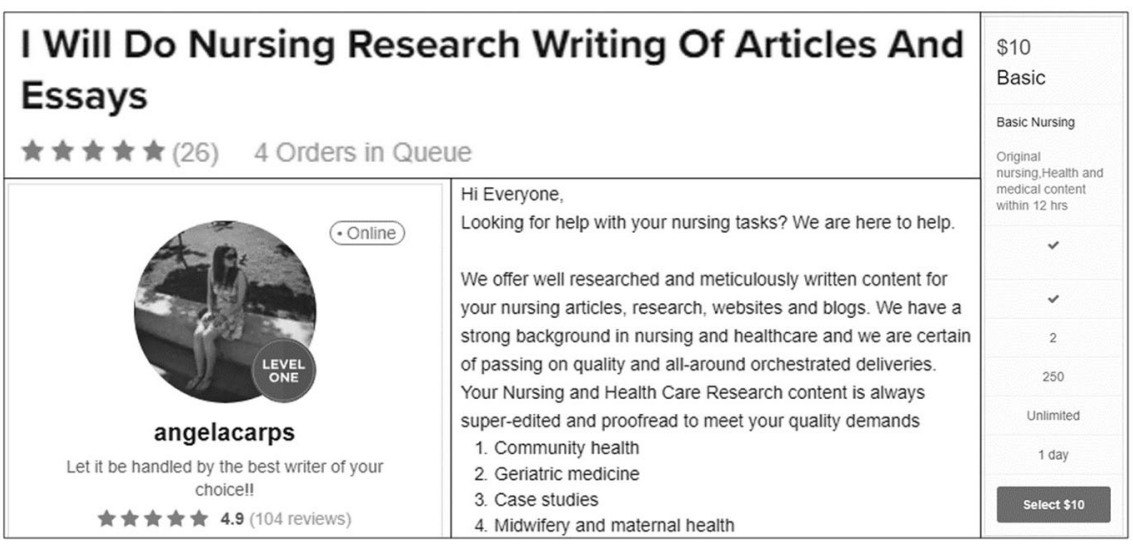

Fig. 2 Example of evidence available from a Gig providing nursing essays found on Fiverr.com 
associated orienting framework within which it was developed, and potential limitations can be found in the previous paper.

Specifically, Fiverr.com was searched for Gigs advertising using the search term "write essay". The information relating directly to the Gig and to the provider behind the Gig was examined and recorded. The examination took into account the observation that some providers may advertise contract cheating services under more than one Gig. Gigs were only considered as in scope for the study if a minimum of one review for that Gig had been received during the past month, indicating that this was an actively trading Gig. Where a provider offered a Gig with a range of pricing options, the cheapest pricing option was recorded.

The data collected related to the Gig itself and the associated provider. The data available for the Gig included the pricing information, the text used in advertising, the timing and frequency of reviewed orders, the rating and number of reviews. The Gig information was supplemented with information about the providers, such as their stated credentials and advertised location.

The earlier example shown surrounding Fig. 2 provides an indicative case study of how the information for one Gig and its associated provider profile could be interpreted in practice.

\section{Results and discussion}

An analysis of the data sets for active providers on Fiverr.com between June 2016 and October 2018 reveals several changes. Key to this is an increase in the number of active providers offering services under the "write essays" search term, accompanied by a corresponding decrease in the total number of visible orders that those providers had produced. Table 1 provides a summary of some key features of the two data sets.

The number of active providers shows an increase of 118.3\% between June 2016 and October 2018. Pricing shows a substantial decrease. This has been calculated from provider advertised pricing, assuming all their previous orders for essays were either 2000 words or 5000 words long. Previously, longer essays carried a small premium, presumably because writing one longer essay is considered to be more work than preparing several shorter essays. The premium now barely exists, showing the mean price point as being \$11.46 USD for a 2000 word essay and \$28.73 USD for a 5000 word essay.

Contract cheating related Gigs on Fiverr.com do not seem to remain active for as long as they did previously. Considering only current Gigs, the minimum possible total number of orders for each has been calculated based on the number of reviews received. This is likely to be a substantial underestimate, since not all customers leave reviews. This data shows a drop in the total number of orders that are visible from 4294 to 1137. Although it may be the case that fewer customers are choosing to leave reviews, it instead appears more likely that Fiverr.com Gigs are not staying active for as

Table 1 Contract cheating providers on Fiverr.com

\begin{tabular}{lll}
\hline Data Set & June 2016 & October 2018 \\
\hline Number of active unique providers offering Gigs under the "write essays" search term & 93 & 197 \\
Mean pricing per 1000 words, assuming all essays were 2000 words long & 31.73 & 5.73 \\
Mean pricing per 1000 words, assuming all essays were 5000 words long & 35.98 & 5.75 \\
Total number of orders for "write essays" Gigs from active providers & 4294 & 1137 \\
\hline
\end{tabular}


long as they were before. Providers are limited in the number of Gigs they can advertise at one time, so they may be choosing to delete these and launch alternative Gigs. This would afford them the opportunity to remove bad reviews, to change their pricing structure or to compete for orders under alternative search terms.

The argument that Gigs are not staying active for long is also supported by an analysis of the timing of reviews. From the October 2018 data set, 669 out of the 1137 known reviews of essays (58.8\%) were dated within the previous month. Further, it appears that providers themselves are not staying active on Fiverr.com. Only 2 of the 93 providers (2.2\%) for "write essays" from June 2016 were still active in October 2018. Although it is possible that some providers may no longer be advertising Gigs under the search term used and some providers may have closed accounts and opened new ones, it appears likely that a new batch of contract cheating providers, willing to work for lower prices than before, has emerged.

The stated location of the providers in the October 2018 data set is of interest, as is the number of orders they obtained. This is shown in Table 2.

As with the June 2016 data, the majority of observed contract cheating providers are from Kenya. This represents an increase from 30.1\% of all providers in June 2016 to $38.1 \%$ of providers in October 2018. This also shows an increase in the raw numbers, as with all contract cheating providers observed on Fiverr.com. The percentage of providers in Pakistan also shows substantive growth, moving from $16.1 \%$ of providers in June 2016 to 29.4\% of providers in October 2018.

Providers from Kenya also received the majority of orders, a cumulative total of 512 out of 1137 orders $(45.0 \%)$, as well as the highest mean number of orders per provider (6.8, almost double the mean number across all providers). An analysis restricted solely to orders in the previous month showed that contract cheating providers from Kenya received 277 out of 669 (41.4\%) of these.

The pricing of providers by country in October 2018 is also worthy of discussion. The two providers who completed the most essays for students also priced their services at a low price. The most prolific provider, from Pakistan, who had completed 56 orders charged only \$4 USD for 2000 words, interestingly billing themselves as being a "sexy engineer by day, writer by night". The second most prolific provider, from Kenya, had completed 50 orders, with a price point of \$5 USD for a 2000 word essay.

Table 3 shows the mean pricing based on stated provider location and assuming all sales were 2000 word essays. This demonstrates a slight premium for orders stated to be from the United States and a slight price decrease for orders from Pakistan. But,

Table 2 Stated locations of contract cheating providers on Fiverr.com

\begin{tabular}{lll}
\hline Stated Provider Location & Number of Providers & Mean Number of Orders Per Provider \\
\hline Kenya & 75 & 6.8 \\
Pakistan & 58 & 4.6 \\
Nigeria & 19 & 8.7 \\
United States & 16 & 5.2 \\
India & 7 & 3 \\
United Kingdom & 5 & 4.6 \\
Other locations (all 3 providers or below) & 17 & 4.0 \\
& Total $=197$ & Overall Mean $=3.4$ \\
\hline
\end{tabular}


considered overall, the price differences do not appear to be substantial enough for a customer to choose a contract cheating provider from one country over another based on price alone.

The overall income from contract cheating services is of interest. Assuming that the figure of 669 reviewed Gigs per month is consistent across the year and that these are 2000 word essays at the stated provider price points, this equates to contract cheating industry revenue of $\$ 92,001$ USD per year. This figure is likely to be an underestimate of the real value, since not all orders are reviewed, many will be for essays longer than 2000 words and some students will opt for the higher priced services offered through many Gigs. Further, this analysis only considers Gigs advertised under the "write essays" search term.

Fiverr.com also takes commission from this process, charging both buyers and sellers. Buyers contribute on a sliding scale with a minimum of \$1 USD. Sellers are charged $20 \%$ of their takings from sales. Taking $\$ 8028$ USD from buyers and \$18,400 USD from sellers, the firm is themselves receiving a minimum of $\$ 26,428$ USD per year as an enabler of contract cheating. The real figure is again likely to be much higher.

Taken collectively, this data continues to demonstrate that contract cheating is a major problem. Contract cheating does not one that exists solely in essay mills and through other such services that are already comprehensively discussed in the academic literature. The reality is that alternative services used by the contract cheating industry are also being used by students. Providers can connect with students using new methods. Many workers can be seen to operate individually and hence undercut the pricing of traditional providers who would take a large commission from every sale. This helps to make the services offered by individual workers seem more affordable by the typical student.

The original study (Lancaster 2019b) discussed six main findings, all of which still hold true. These findings were:

- Individual providers use micro outsourcing sites to connect directly with customers

- Academic ghost writing is a high turnover, low paid profession

- Essay mill like operations exist within Fiverr.com

- Plagiarism detection software is susceptible

- The advertising of contract cheating services is blatant

Table 3 Pricing of contract cheating providers on Fiverr.com by location

\begin{tabular}{ll}
\hline Stated Provider Location & Mean Pricing Of Providers Per 1000 Words, In USD \\
\hline Kenya & 6.09 \\
Pakistan & 4.17 \\
Nigeria & 5.66 \\
United States & 7.64 \\
India & 5.24 \\
United Kingdom & 6.5 \\
Other locations & 6.75 \\
(all 3 providers or below) & \\
& Mean $=5.73$ \\
\hline
\end{tabular}


- The issue of Kenyan academic ghost writers circumventing academic integrity needs to be addressed

The major change observed from the latest data has been the increased use of Fiverr.com for commercial contract cheating. This is accompanied by further discounting of contract cheating services. Workers from Kenya remain prevalent in the system, supported by those from Pakistan. But the data set reveals a huge variety of individuals involved in work as contract cheating providers, ranging from high school and college students, to M. Phil students, to qualified nurses. Many of these workers advertise credentials that on paper look excellent. Some providers, particularly those from developed countries, present their services as merely being one of their hobbies. Multiple providers stress that the work they produce will be plagiarism free and several offer plagiarism reports through services such as Turnitin to allow customers to verify that this is the case.

\section{Conclusions and recommendations}

This paper has provided an expanded analysis of what is known about the use of Fiverr.com for contract cheating. The discussion develops on a research study that was previously presented (Lancaster 2019b). It also addresses a limitation of the earlier investigation, that, at the time, only one data point was available.

The work to analyse the use of contract cheating industry enabling sites such as Fiverr.com is only just beginning. One recommendation to allow academia to continue to learn more about the contract cheating industry is that the collection and analysis of data from sites such as Fiverr.com needs to be automated. This will allow the data to be continually explored and changes to the industry tracked. This is an improved solution on the approach used in this paper of just presenting snapshots at given moments in time.

Educational establishments need to adapt to the continually changing contract cheating marketplace. At a minimum, they should follow the best practice recommendations given to the sector, as well as those for their individual subject discipline. Educational establishments need to ensure that their staff are aware that contract cheating is happening. They need staff to be alert to indicators of contract cheating when marking. The academic integrity processes in use need to be current, robust and regularly reviewed to address the continual changes in technology and the new methods that contract cheating providers are using to try and maintain their market share.

The intention of this paper is not to restate all the good advice that already exists for higher education teachers and institutions that are looking to address contract cheating. It remains the case that teachers should look to set assessments that are of value to students in their learning journey and not tempting for them to outsource. They should consider requiring the student to engage at a local level where their ability and participation can be directly observed. But with low-cost providers directly marketing to students, it may be that more powerful action is needed. Some countries, such as the United Kingdom and Australia, are exploring methods to make advertising contract cheating services illegal. It may be necessary to work to try and convince microoutsourcing services such as Fiverr.com to voluntarily block contract cheating services from trading through them, but this could be difficult, considering that Fiverr.com 
stands to lose an estimated minimum of $\$ 26,428$ USD per year if they elect not to process these transactions.

The difficult and challenging conversations regarding the importance of academic integrity need to be undertaken. Students should be made aware that their tutors are alert to the existence of contract cheating services. Teachers and students need to know that the contract cheating industry is firmly established and is one that is undergoing constant change. Engaging with this industry can be dangerous to students; scams and threats of blackmail are believed to be common. Many academics would argue that contract cheating has reached its current high levels precisely because the early warning signs about the growth of contract cheating were ignored. Contract cheating is a challenge that is likely to grow to epidemic proportions if urgent measures are not put into place to address the growth of the contract cheating industry through all its marketing channels.

\section{Abbreviations}

USD: United States Dollars; UK: United Kingdom

\section{Author's contributions}

The sole author wrote and conceived all aspects of this paper. The author read and approved the final manuscript.

Funding

The author received no funding for this research.

\section{Availability of data and materials}

An anonymised version of the quantitative data analyzed during the current study is available from the author on reasonable request.

\section{Competing interests}

The author declares they have no competing interests.

Received: 3 August 2020 Accepted: 17 August 2020

Published online: 26 August 2020

\section{References}

Amigud A, Lancaster T (2019) 246 reasons to cheat: an analysis of students' reasons for seeking to outsource academic work. Comput Educ 134:98-107

Clarke R, Lancaster T (2006) Eliminating the successor to plagiarism? Identifying the usage of contract cheating sites. In: Proceedings of 2 nd international plagiarism conference. JISC Plagiarism Advisory Service, Newcastle

Ellis C, Zucker I, Randall D (2018) The infernal business of contract cheating: understanding the business processes and models of academic custom writing sites. Int J Educ Integr 14(1):1

Hersey C, Lancaster T (2015) The online industry of paper mills, contract cheating services, and auction sites. Clute Institute Education Conference, London

Jenkins T, Helmore S (2006) Coursework for cash: the threat from online plagiarism. In: Proceedings of 7th Annual Higher Education Academy Conference in Information and Computer Sciences. Higher Education Academy, Dublin

Lancaster T (2019a) Contract cheating in the gig economy. International Center for Academic Integrity Conference 2019, New Orleans

Lancaster T (2019b) Profiling the international academic ghost writers who are providing low-cost essays and assignments for the contract cheating industry. J Inf Commun Ethics Soc 17(1):72-86

Lancaster T (2019c) The emergence of academic ghost writers from India in the international contract cheating industry. Int J Indian Cult Bus Manage 18(3):349-367

Lancaster T, Clarke R (2007) The phenomena of contract cheating. In: Roberts T (ed) Student plagiarism in an online world: problems and solutions, pp 144-158

Lancaster T, Clarke R (2014) An observational analysis of the range and extent of contract cheating from online courses found on agency websites. In: Proceedings of 2014 Eighth International Conference on Complex, Intelligent and Software Intensive Systems (CISIS). Birmingham, IEEE, pp 56-63

Lancaster T, Clarke R (2016) Contract cheating: the outsourcing of assessed student work. In: Bretag T (ed) Handbook of academic integrity, pp 639-654

Lines $L$ (2016) Ghostwriters guaranteeing grades? The quality of online ghostwriting services available to tertiary students in Australia. Teach High Educ 21(8):889-914

Medway D, Roper S, Gillooly L (2018) Contract cheating in UK higher education: A covert investigation of essay mills. Br Educ Res J 44(3):393-418

Newton P (2018) How common is commercial contract cheating in higher education and is it increasing? Front Educ 3:67

Owings S, Nelson J (2014) The essay industry. Mt Plains J Bus Econ 15:1-21 
Quality Assurance Agency. 2017. Contracting to cheat in higher education - how to address contract cheating, the use of third-party services and essay mills. http://www.qaa.ac.uk/en/Publications/Documents/Contracting-to-cheat-in-highereducation.pdf (20.09.19)

Rigby D, Burton M, Balcombe K, Bateman I, Mulatu A (2015) Contract cheating and the market in essays. J Econ Behav Organ 111:23-37

Rogerson A (2017) Detecting contract cheating in essay and report submissions: process, patterns, clues and conversations. Int J Educ Integr 13(1):10

Sivasubramaniam S, Kostelidou K, Ramachandran S (2016) A close encounter with ghost-writers: an initial exploration study on background, strategies and attitudes of independent essay providers. Int J Educ Integr 12(1):1

Stavisky L (1973) Term paper mills, academic plagiarism, and state regulation. Polit Sci Quart 88(3):445-461

Sutherland-Smith W, Dullaghan K (2019) You don't always get what you pay for: user experiences of engaging with contract cheating sites. Assess Eval High Educ 44(8):1148-1162

Walker C (2017) Nairobi shadow academy: a study of contract cheaters (academic writers) in Kenya. In: Plagiarism across Europe and beyond. European Network for Academic Integrity, Brno

Walker C (2020) The white-collar hustle: academic writing \& the Kenyan digital labour economy. University of Oxford, Oxford

Yorke J, Sefcik L, Veeran-Colton T (2020) Contract cheating and blackmail: a risky business? Stud High Educ:1-14. https://doi. org/10.1080/03075079.2020.1730313

Zheng H, Stokel-Walker C (2018) UK students are being hit by a wave of essay-writing scammers. Wired https://www.wired. co.uk/article/uk-university-essay-cheating-spam (20.09.19)

\section{Publisher's Note}

Springer Nature remains neutral with regard to jurisdictional claims in published maps and institutional affiliations.

Ready to submit your research? Choose BMC and benefit from:

- fast, convenient online submission

- thorough peer review by experienced researchers in your field

- rapid publication on acceptance

- support for research data, including large and complex data types

- gold Open Access which fosters wider collaboration and increased citations

- maximum visibility for your research: over $100 \mathrm{M}$ website views per year

At $B M C$, research is always in progress.

Learn more biomedcentral.com/submissions 